\title{
Obstetrical Considerations and Management of Antiphospholipid Syndrome
}

\author{
Karen J. Gibbins* and Robert M. Silver
}

Department of Obstetrics and Gynecology, University of Utah Health Sciences Center and Intermountain Healthcare, 30 N Medical Drive, Salt Lake City, UT 84132, USA

\begin{abstract}
Antiphospholipid syndrome is a pro-thrombotic, pro-inflammatory condition defined by at least one clinical criterion and one laboratory finding. Clinical criteria are met by history of thrombosis or obstetric morbidity, including recurrent early pregnancy loss, fetal death, or delivery prior to 34 weeks gestation due to pre-eclampsia or placental insufficiency. Laboratory criteria are evidence of lupus anticoagulant or high titers of anticardiolipin or anti- $\beta_{2^{-}}$ glycoprotein-I IgG or IgM. Treatment during pregnancy is primarily based on anticoagulant therapy, either at prophylactic or therapeutic doses depending on thrombosis history. This treatment certainly reduces thrombosis risk and may also improve obstetric outcome.
\end{abstract}

Keywords: Antiphospholipid syndrome, pre-eclampsia, pregnancy loss, stillbirth.

Successful pregnancy resulting in a term delivery, a healthy neonate, and a healthy mother requires a delicate negotiation between maternal and fetal physiologies. This interplay hinges upon the development of a complex maternal-fetal interface at the placenta, permitting fetal nutrition and perfusion while limiting maternal hemorrhage or compromise. Antiphospholipid syndrome (APS) compromises this balance and is associated with a broad spectrum of obstetric morbidity.

The diagnosis of APS requires both laboratory and clinical findings [1-3] as outlined in Table 1. Detection of specified levels of antiphospholipid antibodies (aPL) fulfills the laboratory criterion. Clinical criteria are more varied, including both vascular thrombosis and obstetric morbidity. Briefly, vascular thrombosis can be venous or arterial, most commonly venous, leading to pulmonary embolism. Any thrombosis without clear etiology warrants evaluation for APS because aPL will be detected in approximately $2 \%$ of these patients [4]. Obstetric morbidity will be discussed extensively below. Despite the clearly outlined criteria, controversy remains regarding both the specifics of the laboratory and clinical features of APS. The presence of aPL without clinical criteria for APS is of unclear diagnostic and prognostic utility, both with regards to vascular as well as obstetric complications.

\section{LABORATORY TESTING}

Antiphospholipid antibodies (aPL) are a form of autoimmunity and comprise varied antibodies to antigens including negatively charged phospholipids, proteins, and

*Address correspondence to this author at the Department of Obstetrics and Gynecology, University of Utah Health Sciences Center and Intermountain Healthcare, $30 \mathrm{~N}$ Medical Drive, Salt Lake City, UT 84132, USA;

Tel: 801-581-8425; Fax: 801-585-5146;

E-mail: Karen.gibbins@hsc.utah.edu combinations of the two. Many aPL have been studied in an attempt to find the most reproducible assays and the aPL that best correlate with clinical problems. To date, lupus anticoagulant, anticardiolipin antibodies and anti- $\beta_{2^{-}}$ glycoprotein-I antibodies are the best characterized and are part of the current diagnostic criteria for APS. Historically, there has been wide variance in laboratory quality control that has complicated comparing the findings amongst different laboratories [5]. This has led to a focus on centralized, validated laboratories running the assays using consistent and standardized protocols.

The lupus anticoagulant (LA) is neither diagnostic of lupus nor a result of anticoagulation. It gained its inopportune name from initial identification in lupus patients and making clotting assays appear as though the patient was anticoagulated. These antibodies interfere with phospholipid dependent clotting assays, thus prolonging the clotting time. Many tests are affected by this antibody, including the dilute Russel viper venom time, the activated partial thromboplastin time (aPTT), the plasma clotting time, and the Kaolin clotting time, but typically the prothrombin time is spared. Unlike the other two aPL assays of focus, the LA is reported as either present or absent and not as a specific titer value.

Both the anticardiolipin antibodies and anti- $\beta_{2^{-}}$ glycoprotein-I antibodies are assessed by ELISA and reported in standard titer format. Values are levels of $\operatorname{IgG}$ or $\operatorname{IgM}$, with anticardiolipin antibodies reported as GPL or MPL and anti- $\beta_{2}$-glycoprotein-I antibodies reported as SGU and SMU. The current accepted threshold for the diagnosis of APS is $\geq 40$ for all values, although historic studies often used lower and thus less specific cutoff levels. All tests may be transiently elevated (e.g. in infectious/inflammatory settings) and thus must be confirmed with repeat testing in greater than 12 weeks to confirm the diagnosis of APS. 
Table 1. Revised classification criteria for diagnosis of the antiphospholipid antibody syndrome (APS).

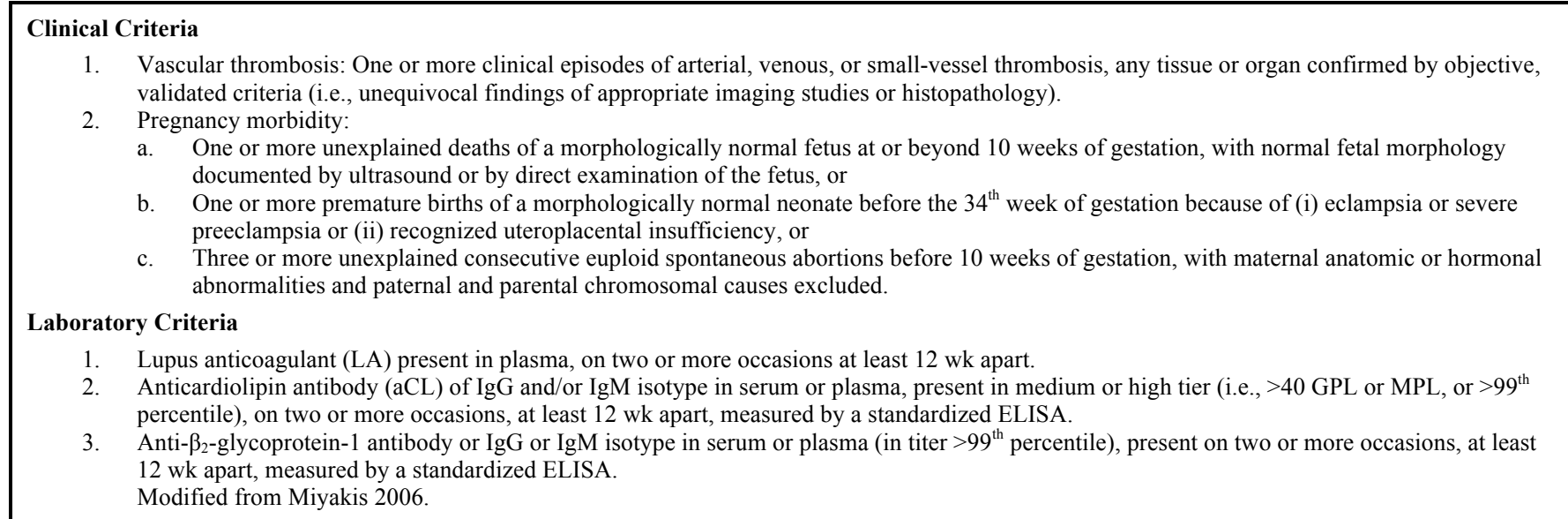

\section{MEDICAL COMPLICATIONS}

Pregnant women with APS are subject to the same medical complications as non- pregnant individuals with APS. The most common is thromboembolism, and the risk is further increased by pregnancy. The rate of venous thromboembolism in pregnant women with APS ranges from $5-12 \%$ and extends into the postpartum period [6, 7]. Venous or arterial thromboembolism in pregnancy is treated with unfractionated heparin or low molecular weight heparin anticoagulation. Postpartum women can be transitioned to oral anticoagulation if desired. Patients are also at risk for APS associated autoimmune thrombocytopenia, which is clinically quite similar to idiopathic thrombocytopenic purpura [8].

Throughout pregnancy and particularly postpartum, clinicians must also remain vigilant for other medical complications of APS, including catastrophic APS (CAPS), a highly morbid disease involving diffuse thrombosis of small and large vessels resulting in multisystem organ failure [9-11]. These thromboses are most often found on histopathology of the kidneys, lungs, and gastrointestinal tract with sparing of the heart, liver, and adrenal glands. A review of 50 affected patients found renal involvement on presentation in $78 \%$, often with concomitant malignant hypertension [12]. Pulmonary involvement was present in $66 \%$ of patients, with severe dyspnea as a common symptom. Of these patients, half progressed to ARDS and one-fourth were diagnosed with pulmonary embolism. Many also had central nervous system involvement with confusion, stupor, seizures, hemorrhage, and infarction. Severe abdominal pain, mesenteric ischemia, skin necrosis, purpura, and myocardial infarctions are often present. In a review focusing on 15 cases of CAPS in pregnant women, renal involvement and pulmonary involvement remained most common ( $>70 \%$ of cases), with CNS involvement $(60 \%)$ and HELLP syndrome (53\%) also frequent [13]. $46 \%$ of mothers died in this case series. CAPS is often triggered by an identifiable factor, such as infection, trauma, and surgery. $6 \%$ of identified cases occur during pregnancy or puerperium [14]. Treatment is as with any aggressive, systemic microangiopathy: primarily supportive care. This can involve antihypertensive treatment, ventilator support, dialysis, vasopressors, plasmapheresis, intravenous immuno- globins, anticoagulation, and steroids. CAPS is highly mortal with a $50 \%$ to $65 \%$ rate of death.

\section{OBSTETRIC COMPLICATIONS}

Pregnancy specific complications secondary to APS are varied and include recurrent early pregnancy loss, fetal death, stillbirth, pre-eclampsia, fetal growth restriction, placental abruption, and placental insufficiency expressed as oligohydramnios (low levels of amniotic fluid) and/or abnormal fetal heart tracing or umbilical artery Doppler assessment. All of these complications convey a high risk of preterm birth or fetal loss and thus, significant fetal and neonatal morbidity. The data linking aPL and these adverse pregnancy outcomes are primarily from case-control studies, are varied in both the presence and strength of association, and often lack repeat confirmatory laboratory testing.

The association between aPL and early pregnancy loss is controversial. A recent systematic review [15] queried studies that included first trimester loss and aPL testing. The researchers found high variability between presence or absence of an association, the titer cutoffs used to signify a positive test, and the rates of confirmatory testing in a standardized lab. It appears that APS is more strongly associated with fetal death than with early pregnancy loss (embryonic, pre-embryonic, and implantation failure), with more than $50 \%$ of losses after gestation week 10 and higher rates of detectable embryonic cardiac activity prior to loss [16-18]. Sporadic early pregnancy loss (prior to 10 weeks' gestation) is not associated with aPL, likely given the high majority of these losses due to genetic reasons [19]. Although there is an association between aPL and recurrent early pregnancy loss in women without another explanation, this association remains poorly defined. Despite recurrent early pregnancy loss being listed as a clinical criterion for APS, it remains controversial.

Although most late complications of placental insufficiency are not secondary to APS, women with APS have higher rates of these disorders, such as preeclampsia, fetal growth restriction, and abnormal fetal testing prompting either induction of labor (both at term and preterm) or Cesarean. Women with well-characterized, true APS have rates of preeclampsia as high as $25-50 \%$ and rates of fetal 
growth restriction (defined as fetal growth less than the $10^{\text {th }}$ percentile) as high as $15-30 \%[20,21]$. Pre-eclampsia in women with true APS is typically early onset and severe. High levels of aCL antibodies have a strong association with fetal growth restriction.

The diagnosis of APS using only the clinical criterion of preeclampsia or placental insufficiency, however, is less clear. Two published meta-analyses analyzing aPL and preeclampsia exist. One grouped 12 studies and found an increased incidence of aCL among women with severe preeclampsia (OR 11.15, 95\% CI 2.66-46.75) [22]. However, aPL were not associated with mild preeclampsia [23]. The second meta-analysis evaluated all three aPL and the adverse pregnancy outcomes of pre-eclampsia, fetal growth restriction, placental abruption, and stillbirth [24]. They found LAC and aCL to be more common in preeclampsia in 10 case-control studies but not in three cohort studies. Anti- $\beta_{2}$-glycoprotein-I antibodies were more common in preeclamptic patients in cohort studies but not in case-control studies. Many studies included in these metaanalyses used antibody titer cutoffs well below current guidelines and did not confirm elevated values with repeat testing. Although there appears to be association between aPL and placental insufficiency related adverse pregnancy outcomes, particularly more severe ones, available data remain inconclusive and further studies using more rigorous laboratory cutoffs and assays are needed.

aPL is associated with higher rates of stillbirth. In a population based case-control study of women with stillbirths, when stillbirths not associated with obstetric complications or fetal anomalies were compared with live births, there were elevated levels of IgG aCL (5\% versus $1 \%$; OR 5.30, 95\% CI 2.39-11.76), IgM aCL (6\% versus 3\%, OR 2.03, 95\% CI 1.09-3.76), and IgG anti-2-glycoprotein-I (1.9\% versus $0.6 \%$; OR 3.0, 95\% CI 1.01-8.90) [25]. This is consistent with the current guidelines for diagnosing APS. Although overall rates of APS are rare, testing for aPL is warranted in cases of otherwise unexplained stillbirth.

There is also an ill-defined association between aPL and subfertility. When women with infertility or subfertility are tested, they have higher rates of aPL [22, 23]. However, there was no difference in either clinical pregnancy (OR $0.99 ; 95 \%$ CI $0.64-1.53$ ) or live birth rate (OR 1.07; 95\% CI 0.66-1.75) when women undergoing in vitro fertilization were compared by presence or absence of aPL [26]. Moreover, treating aPL positive women with anticoagulant therapy does not improve outcomes of their in vitro fertilization cycle [27]. Therefore, we believe that patients with infertility do not warrant screening for aPL.

\section{PATHOPHYSIOLOGY}

The pathophysiology of APS with regard to adverse pregnancy outcomes is incompletely understood, but likely involves both thrombotic and inflammatory pathways (which appear symbiotic). By binding to antiphospholipid-binding proteins including $\beta_{2}$-glycoprotein-1 and annexin $\mathrm{V}$, aPL limit intrinsic anticoagulation. They also increase tissue factor, PAI-1, and vWF expression in endothelial cells; inhibit thrombomodulin, aPC, and antithrombin activity, and enforce platelet activation, all leading to a procoagulant environment [28, 29]. Theoretically, thrombosis of the placental villous bed would lead to infarction on a micro or macro level and limit oxygen supply to the developing pregnancy, with the outcome depending on both the timing and extent of thrombosis. This, however, is likely an oversimplification of the problem.

Given that pregnancy prior to 10 weeks gestation is a low-oxygen environment with trophoblast plugging the spiral arteries and low intervillous oxygen pressures $[30,31]$, it is unlikely that thrombosis alone would explain the association between aPL and early pregnancy loss (although it could contribute to later adverse pregnancy outcomes). Inflammation in the placenta in the absence of infection can be triggered by aPL as well. The complement pathway seems to be critical in aPL induced fetal loss and fetal growth restriction in a murine model [32]. Furthermore, blocking the complement pathway by either genetic knockouts or complement factor specific antibodies salvages these effects [33-36]. There is evidence for elevated complement activation in patients with APS as well $[37,38]$.

\section{TREATMENT}

The primary focus of obstetric management of APS is to decrease thrombosis risk. Women with APS and previous thrombotic event are typically on lifelong anticoagulation, frequently with warfarin compounds. They should be transitioned to full anticoagulation with either unfractionated heparin (UH) or low molecular weight heparin (LMWH) as soon as pregnancy is recognized. Oral anticoagulation can be reinitiated postpartum. If women with APS have not had a prior thrombosis, the treatment strategy is less standard. The majority of experts recommend thromboprophylaxis with UH or LMWH from knowledge of pregnancy until 6 weeks postpartum (with brief peri-delivery cessation). This is primarily to prevent thrombosis during this time of increased risk.

Although many clinicians believe that UH and LMWH have the potential to ameliorate late adverse pregnancy outcomes potentially by reducing placental thrombosis, its efficacy is unproven [39]. Women who are diagnosed with APS on the basis of recurrent early pregnancy loss are typically treated with UH or LMWH along with low dose aspirin, with the belief that this improves live birth rates. However, existing data are conflicting, and no randomized, placebo-controlled trial has ever been performed. In three of five studies comparing $\mathrm{UH}$ and low dose aspirin to low dose aspirin alone, there was an improvement in live birth rates [40-42]. In contrast, there was no improvement in two other studies [43, 44]. Overall, these five studies included 353 women, and the stringency of inclusion criteria was variable. If heparin does, in fact, improve clinical outcomes in this cohort of APS patients, it may be secondary to heparin's anti-inflammatory, anti-complement qualities and not due to its anti-thrombotic properties [45].

Prednisone at doses of 40mg daily and higher has been evaluated in the treatment of APS. Although this yielded successful pregnancy rates of $60-70 \%$, there was not a significant difference when compared to women who received heparin alone. Additionally, women who received prednisone had higher rates of preterm labor, preterm 
premature rupture of membranes and pre-eclampsia [46]. Prednisone rapidly fell out of favor, particularly given heparin's utility in thrombosis prevention.

Women who are treated with heparin compounds are at increased risk for heparin-induced osteopenia. They should be encouraged to maintain adequate calcium intake and weight bearing exercise. Other side effects of heparin compounds include bleeding, easy bruising, and thrombocytopenia. LMWH has a lower risk for osteopenia or thrombocytopenia than UH and is typically preferred during pregnancy due to an improved side effect profile. However, trials of comparative efficacy are lacking.

Considering the link between APS and inflammation, anti-inflammatory compounds are sometimes used by experts to treat particularly recalcitrant obstetric APS. These include hydroxychloroquine, IVIG, plasmapheresis, aspirin, anti-TNF agents, and rituximab (an anti-CD20 monoclonal antibody that targets $\mathrm{B}$ cells). If practitioners choose to consider these agents, it is important to counsel women that there are no clinical, human data to support this use. All of these compounds warrant further study to either support or refute their efficacy.

Although unsupported by randomized-controlled trials, it is reasonable to consider standard antenatal testing including non-stress tests and biophysical profiles for women with APS given their increased incidence of placental insufficiency. We also recommend serial ultrasounds to evaluate fetal growth. There is evidence that uterine artery Doppler with elevated resistance index or an early diastolic notch at mid-trimester is predictive of subsequent fetal growth restriction and delivery prior to 34 weeks gestation [47]. Similarly, abnormal second trimester umbilical artery end diastolic indices may also predict fetal or neonatal death, although normal indices do not ensure good outcome [48]. One of the primary goals of standard prenatal care is surveillance for and early detection of pre-eclampsia. Women should also be well educated regarding warning signs of both pre-eclampsia and maternal thrombotic disease.

Given that women with APS are at lifelong increased risk of thrombosis, women should avoid estrogen based contraception after pregnancy [49]. These include combined oral contraceptives, the contraceptive transdermal patch, and the contraceptive vaginal ring. Progestin containing contraceptives are not prothrombotic and are both safe and recommended for women with APS. These include the progestin containing intrauterine device (IUD), the progestin implant, injectable depot medroxyprogesterone acetate, and progestin pills (which are the least effective).

\section{SUMMARY}

APS causes a pro-thrombotic, pro-inflammatory state in the parturient which puts her at risk for thrombosis, pregnancy loss, and problems related to placental insufficiency. Heparin compounds are the mainstay of treatment of this disorder throughout gestation until six weeks postpartum, with the main goal of preventing maternal thrombosis. It is possible that heparin compounds or antiinflammatory therapeutics may modify the risk for adverse pregnancy outcomes in women with APS, but this requires further evaluation.

\section{CONFLICT OF INTEREST}

The authors confirm that this article content has no conflict of interest.

\section{ACKNOWLEDGEMENTS}

Declared none.

\section{REFERENCES}

[1] ACOG Practice Bulletin No. 118: Antiphospholipid Syndrome. Obstet Gynecol 2011; 117: 192-9.

[2] Galli M, Luciani D, Bertolini G, et al. Anti-beta 2-glycoprotein I, antiprothrombin antibodies, and the risk of thrombosis in the antiphospholipid syndrome. Blood 2003; 102: 2717-23.

[3] Miyakis S, Lockshin MD, Atsumi T, et al. International consensus statement on an update of the classification criteria for definite antiphospholipid syndrome (APS). J Thromb Haemost 2006; 4: 295-306.

[4] Lockwood CJ, Romero R, Feinberg RF, et al. The prevalence and biologic significance of lupus anticoagulant and anticardiolipin antibodies in a general obstetric population. Am J Obstet Gynecol 1989; 161: 369 .

[5] Erkan D, Derksen WJ, Kaplan V, et al. Real world experience with antiphospholipid antibody tests: how stable are results over time? Ann Rheum Dis 2005; 64: 1321-5.

[6] Crowther MA, Ginsberg JS, Julian J, et al. A comparison of two intensities of warfarin for the prevention of recurrent thrombosis in patients with the antiphospholipid antibody syndrome. $\mathrm{N}$ Engl J Med 2003; 349: 1133-8.

[7] Branch DW, Silver RM, Blackwell JL, et al. Outcome of treated pregnancies in women with antiphospholipid syndrome: An update of the Utah experience. Obstet Gynecol 1992; 80: 614-20.

[8] Harris EN, Asherson RA, Gharavi AE, et al. Thrombocytopenia in SLE and related autoimmune disorders: association with anticardiolipin antibody. Br J Haematol 1985; 59: 227-30.

[9] Kochenour NK, Branch DW, Rote NS, Scott JR. A new postpartum syndrome associated with antiphospholipid antibodies. Obstet Gynecol 1987; 69: 460-8.

[10] Kupferminc MJ, Lee MJ, Green D, Peaceman AM. Severe postpartum pulmonary, cardiac and renal syndrome associated with antiphospholipid antibodies. Obstet Gynecol 1994; 83: 806-7.

[11] Thielen N, Bolte AC, Zweegman S, Chamuleau MED. Catastrophic antiphospholipid syndrome in the obstetric period. Eur J Obstet Gynecol Reprod Biol 2012; 160: 236-40.

[12] Asherson RA, Cervera R, Piette JC, et al. Catastrophic antiphospholipid syndrome. Clinical and laboratory features of 50 patients. Medicine (Baltimore) 1998; 77: 195-207.

[13] Gomez-Puerta JA, Cervera R, Espinosa G, et al. for the Catastrophic Antiphospholipid Syndrome Registry Project Group/European Forum on Antiphospholipid Antibodies. Ann Rheum Dis 2007; 66: 740-6.

[14] Gomez-Puerta JA, Cervera R, Espinosa G, Bucciarelli S, Font J. Pregnancy and puerperium are high susceptibility periods for development of catastrophic antiphospholipid syndrome. Autoimmunity Rev 2006; 6: 85-8.

[15] Andreoli L, Chighizola CB, Banzato A, et al. The estimated frequency of antiphospholipid antibodies in patients with pregnancy morbidity, stroke, myocardial infarction, and deep vein thrombosis. Arthritis Care Res (Hoboken) 2013; 65(11): 1869-73.

[16] Rai RS, Clifford K, Cohen H, et al. High prospective fetal loss rate in untreated pregnancies of women with recurrent miscarriage and antiphospholipid antibodies. Hum Reprod 1995; 10: 3301-4.

[17] Branch DW, Silver RM. Criteria for antiphospholipid syndrome: Early pregnancy loss, fetal loss, or recurrent pregnancy loss? Lupus 1996; 5: 409-13.

[18] Oshiro BT, Silver RM, Scott JR, Yu H, Branch DW. Antiphospholipid antibodies and fetal death. Obstet Gynecol 1996; 87: 489-93.

[19] Branch DW, Khamashta MA. Antiphospholipid syndrome: obstetric diagnosis, management, and controversies. Obstet Gynecol 2003; 101: 1333-44. 
[20] Branch DW, Silver RM, Blackwell JL, et al. Outcome of treated pregnancies in women with antiphospholipid syndrome: an update of the Utah experience. Obstet Gynecol 1992; 80: 614-20.

[21] do Prado AD, Piovesan DM, Staub HL, Horta BL. Association of anticardiolipin antibodies with preeclampsia: a systematic review and meta-analysis. Obstet Gynecol 2010; 116: 1433-43.

[22] Abou-Nassar K, Carrier M, Ramsay T, Rodger MA. The association between antiphospholipid antibodies and placenta mediated complications: a systematic review and meta-analysis. Thromb Res 2011; 128: 77-85.

[23] Silver RM, Parker CB, Reddy UM, et al. Antiphospholipid antibodies in stillbirth. Obstet Gynecol 2013; 122(3): 641-57.

[24] Birkenfeld A, Mukaida T, Minichiello L, et al. Incidence of autoimmune antibodies in failed embryo transfer cycles. Am J Reprod Immunol 1994; 31: 65-68.

[25] Birdsall MA, Lockwood GM, Ledger WL, et al. Antiphospholipid antibodies in women having in-vitro fertilization. Hum Reprod 1996; 11:1185-9.

[26] Hornstein MD, Davis OK, Massey JB, et al. Antiphospholipid antibodies and in vitro fertilization success: A meta-analysis. Fertil Steril 2000; 73: 330-3

[27] Stern C, Chamley L, Norris H, et al. A randomized, double-blind, placebo-controlled trial of heparin and aspirin for women with in vitro fertilization implantation failure and antiphospholipid or antinuclear antibodies. Fertil Steril 2003; 80: 376-83.

[28] Field SL, Brighton TA, McNeil HP, et al. Recent insights into antiphospholipid antibody-mediated thrombosis. Baillieres Best Pract Res Clin Haematol 1999; 12: 407-22.

[29] Rand JH, Wu XX, Andree HA, et al. Pregnancy loss in the antiphospholipid-antibody syndrome: A possible thrombogenic mechanism. N Engl J Med 1997; 337: 154-60.

[30] Rodesch F, Simon P, Donner C, et al. Oxygen measurements in endometrial and trophoblastic tissues during early pregnancy. Obstet Gynecol 1992; 80: 283-5.

[31] Watson AL, Skepper JN, Jauniaux E, et al. Susceptibility of human placental syncytiotrophoblastic mitochondria to oxygen-mediated damage in relation to gestational age. J Clin Endocrinol Metab 1998; 83: 1697-705.

[32] Holers VM, Girardi G, Mo L, et al. Complement C3 activation is required for antiphospholipid antibody-induced pregnancy loss. J Exp Med 2002; 195: 211.

[33] Salmon JE, Girardi G, Holers VM. Activation of complement mediates antiphospholipid antibody-induced pregnancy loss. Lupus 2003; 12: 535-8.

[34] Pierangeli SS, Girardi G, Vega-Ostertag M, Liu X, Espinola RG, Salmon J. Requirement of activation of complement C3 and C5 for antiphospholipid -mediated thrombophilia. Arthritis Rheum 2005; 52: $2120-4$

[35] Romay-Penebad Z, Liu XX, Montiel-Manzano G, Papalardo De Martinez E, Pierangeli SS. C5a receptor-deficient mice are protected from thrombophilia and endothelial cell activation induced by some antiphospholipid antibodies. Ann N Y Acad Sci 2007; 1108: 554-66.

[36] Girardi G, Berman J, Redecha P, et al. Complement C5a receptors and neutrophils mediate fetal injury in the antiphospholipid syndrome. J Clin Invest 2003; 112(11): 1644-54.

[37] Oku K, Atsumi T, Bohgaki M, et al. Complement activation in patients with primary antiphospholipid syndrome. Ann Rheum Dis 2009; 68: 10-30

[38] Lynch AM, Murphy JR, Byers T, et al. Alternative complement pathway activation fragment $\mathrm{Bb}$ in early pregnancy as a predictor of preeclampsia. Am J Obstet Gynecol 2008; 198(4): 385.e1-9.

[39] Branch DW, Silver RM, Porter TF. Obstetric antiphospholipid syndrome: current uncertainties should guide our way. Lupus 2010; 19: 446-452.

[40] Kutteh WH. Antiphospholipid antibody-associated recurrent pregnancy loss: treatment with heparin and low-dose aspirin is superior to low-dose aspirin alone. Am Obstet Gynecol 1996; 174:1584-9.

[41] Rai R, Cohen H, Dave M, Regan L. Rrandomised controlled trial of aspirin and aspirin plus heparin in pregnant women with recurrent miscarriage associated with phospholipid antibodies (or antiphospholipid antibodies). BMJ 1997; 314: 253-7.

[42] Goel N, Tuli A, Choudhry R. The role of aspirin versus aspirin and heparin in cases of recurrent abortions with raised anticardiolipin antibodies. Med Sci Monit 2006; 12: 132-6.

[43] Farquharson RG, Quenby S, Greaves M. Antiphospholipid syndrome in pregnancy: a randomized, controlled trial of treatment. Obstet Gynecol 2002; 100(3): 408-13.

[44] Laskin CA, Spitzer KA, Clark CA, et al. Low molecular weight heparin and aspirin for recurrent pregnancy loss: results from the randomized, controlled HepASA Trial. J Rheumatol 2009; 36(2): 279-87.

[45] Girardi G, Redecha P, Salmon JE. Heparin prevents antiphospholipid antibody-induced fetal loss by inhibiting complement activation. Nat Med 2004; 10: 1222-6.

[46] Cowchock S. Treatment of antiphospholipid syndrome in pregnancy. Lupus 1998; 7: S95-S97.

[47] Farrell T, Dawson T. Can uterine artery Doppler velocimetry predict advers pregnancy outcome in women with antiphospholipid syndrome? Acta Obstet Gynecol Scand 2001; 80: 609-10.

[48] Le Thi Huong D, Wechsler B, Vauthier-Brouzes D, et al. The second trimester Doppler ultrasound examination is the best predictor of late pregnancy outcome in systemic lupus erythematosus and/or the antiphospholipid syndrome. Rheumatology 2006; 45 : 332-8.

[49] Erkan D, Patel S, Nuzzo M, et al. Management of the controversial aspects of the antiphospholipid syndrome pregnancies: a guide for clinicians and researchers. Rheumatology 2008; 47(supp13): 23-7.

Received: July 5, 2014

Revised: September 25, 2014

Accepted: September 25, 2014

(C) Gibbins and Silver; Licensee Bentham Open.

This is an open access article licensed under the terms of the Creative Commons Attribution Non-Commercial License (http://creativecommons.org/licenses/by-nc/3.0/) which permits unrestricted, non-commercial use, distribution and reproduction in any medium, provided the work is properly cited. 